\title{
SCAR ENDOMETRIOSIS: CASE REPORT
}

Onimi Syamala ${ }^{1}, \mathrm{G}$. Usha Rani²

\section{HOW TO CITE THIS ARTICLE:}

Onimi Syamala, G. Usha Rani. "Scar Endometriosis: Case Report". Journal of Evolution of Medical and Dental Sciences 2014; Vol. 3, Issue 55, October 23; Page: 12706-12710, DOI: 10.14260/jemds/2014/3685

ABSTRACT: Endometrosis is presence of functioning endometrial tissue outside the uterine cavity. Endometriosis can sometimes occur on a previous surgical scar. Occurrence of scar endometriosis is rare and difficult to diagnose. It mostly follows obstetrical and gynaecological surgeries. This condition is often confused with surgical condition. In this case series we are enlisting four such cases of scar endometriosis following caesarean section. Initially medical treatment was tried on the all four cases but, it did not give any relief to the patients. All the four patients required surgical excision and on two of them mesh repair of rectus sheath was done along with wide excision.

KEYWORDS: Endometrioma; Endometriosis; Scar endometrioma.

INTRODUCTION: Endometriosis is a common benign gynaecological disorder defined as the presence of endometrial glands and stroma outside the normal location. Annual incidence of surgically diagnosed endometriosis is 1.6 cases per $1000,{ }^{1}$ prevalence is $20-50 \%$ in infertile women, 40-50\% in those with pelvic pain.

Commonest sites are pelvic peritoneum, ovaries; rectovaginal septum ${ }^{2}$.Rare sites are bladder, kidney, ureter pericardium, pleura and surgical scar. Most of the scar endometriosis develops following caesarean section 3 , hysterotomy, hysterectomy, episiotomy ${ }^{4}$ and tubal ligation.

Sri Ramachandra Medical College and Research Institute is a tertiary care referral institute with annual delivery rate of 4000 . We came across four (4) cases of scar endometriosis following caesarean section with a follow up of five (5) years. The women are of ages 27, 32, 35 and 38 and were reported with cyclical pain in the abdomen over the scar. The pain duration was between 2-8 years from the time of surgery (caesarean section) performed and pain was very much localized. After clinical examination of each case medical treatment was tried followed by surgical excision of the scar as there was no relief with the medical management.

\section{The presentation of the four such cases is as Follows:}

CASE 1: A 38 year old woman presented to obstetrics and gynaecology department with cyclical pain in abdomen and swelling over the scar site for the past one year. She previously had two caesarean sections 8 and 5 years ago. Examination revealed that $5 \times 5 \mathrm{~cm}$ mass felt at the left angle of Pfannenstiel scar. She was later taken up for surgery for excision of mass. Mass sent for histopathological examination (Figure 5), confirmed the diagnosis of scar endometriosis. Postoperative period was uneventful. She was discharged after eight days following surgery.

CASE 2: Another woman of 35 years came with pain over the operated site, which was increasing and intensive during cycles for the past 2 years. She had one normal delivery and one caesarean section for twin gestations 8 years ago. She was operated for the mass which was extending up to rectus muscle involving peritoneum. In this patient too, excision was done and it was sent for histopathological examination (Figure 6). The report was confirmed to be scar endometriosis. 


\section{CASE REPORT}

CASE 3: The third patient of 32 years woman presented with pain over the operated site more on the right side of surgical scar for the past 5 years. Pain started after one year of previous caesarean section. She was admitted and all investigations were done including USG ${ }^{5}$, which suggested a mass on right side of LSCS of the surgical scar with a probable diagnosis of hernia or lymphnode. She was taken up for surgery per operatively a mass of $7 \times 5 \mathrm{~cm}$ present over the rectus sheath, same was excised. As the defect was big a prolene mesh was kept and rectus sheath was closed. Histopathology reported as scar endometriosis (Figure 7).

CASE 4: The fourth patient of 27 years presented with pain over the previous LSCS scar more during menstrual cycles. Patient had LSCS 5 years ago. All investigations including FNAC done, FNAC report was inconclusive. USG showed mixed echogenic mass over scar area of $6 \times 2.2 \mathrm{~cm}$, the same was excised and sent of histopathology (Figure 8). As the rent was big, rectus sheath was repaired with prolene mesh.

Follow-Up: All patients are being followed up and have had no recurrence till date.

DISCUSSION: Endometrioma is a well circumscribed mass of endometriosis. Abdominal wall6,7,8 endometriomas present as a painful swelling, resembling surgical lesion such as hernia, haematoma, granulomas, stitch abscess and tumor.

Scar endometrios most commonly occurs after operation on uterus and tubes. Incidence of scar endometriosis after caesarean section is around 0.3 to 0.4 per cent, following hysterotomy 1.08 per cent to 2 per cent. The etiology of abdominal wall endometrioma is thought to be a result of transportation of endometrial tissue during surgical procedures and subsequently stimulated by oestrogen to produce endometriomas. The simultaneous occurrence of pelvic endometriosis with scar endometriosis is infrequent.

Our patients also did not have pelvic endometriosis. Pre-operative diagnosis was difficult to make, the diagnosis was made after excision and histopathological examination. Various diagnostic methods have been described in literature, USG, Doppler and FNAC.

Anecdotal studies have mentioned the use of CT and MRI in making diagnosis. Treatment of choice of all the four patients was excision of mass, and two of the four selected cases required wide excision and mesh repair. Medical treatment tried initially which did not give any relief of symptoms.

To conclude one should have high index of suspicion of scar endometriosis when a woman presented with a painful swelling on abdominal scar especially following gynaecologic and obstetrical surgery. Efforts should be made to make a preoperative diagnosis with the help of imaging technique and FNAC. Medical treatment is not helpful. Wide excision is the treatment of choice and patients should be followed up for recurrence. 


\section{CASE REPORT}
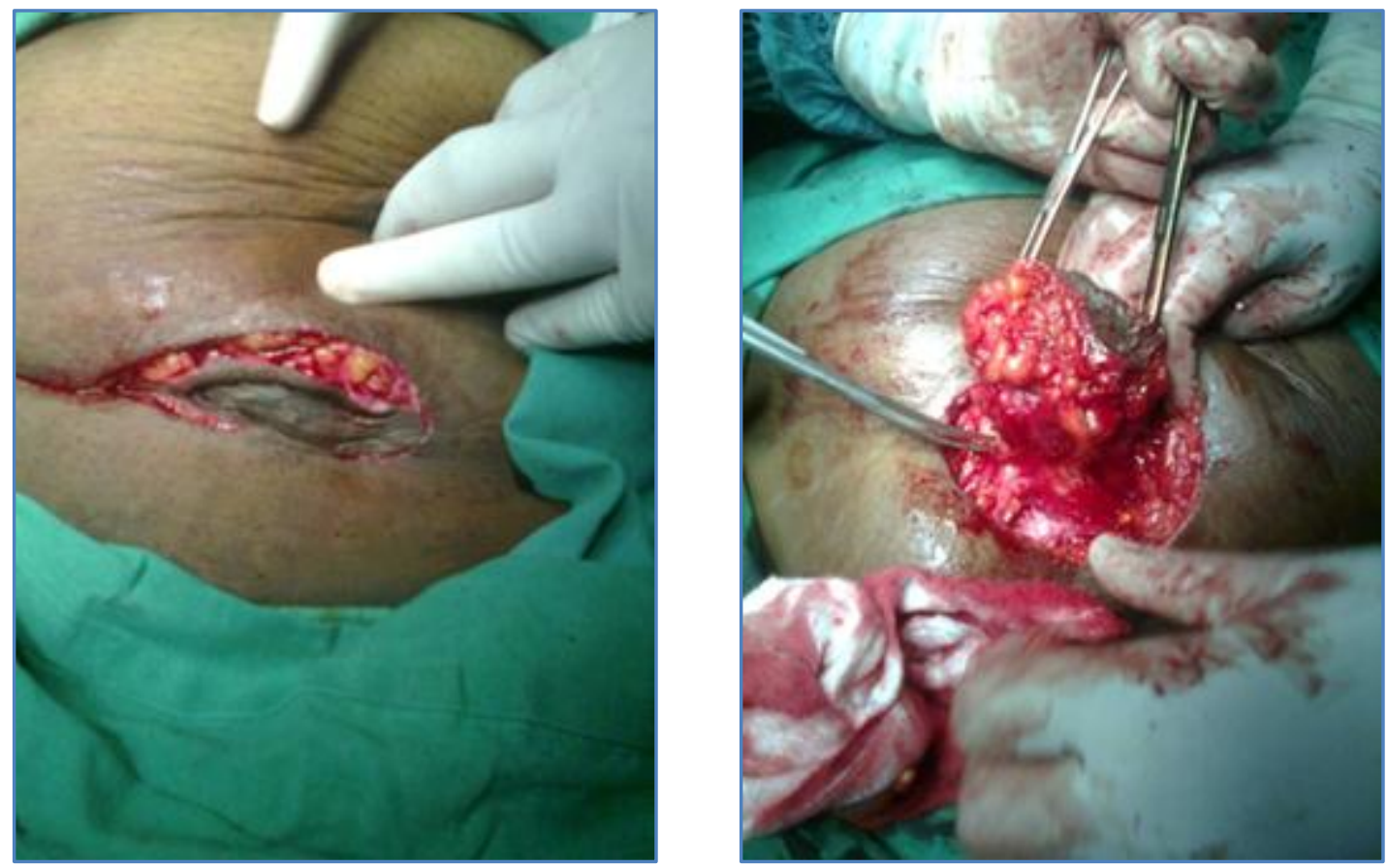

Figure 1 and 2: Scar endometrioma and surgical excision of Case 1
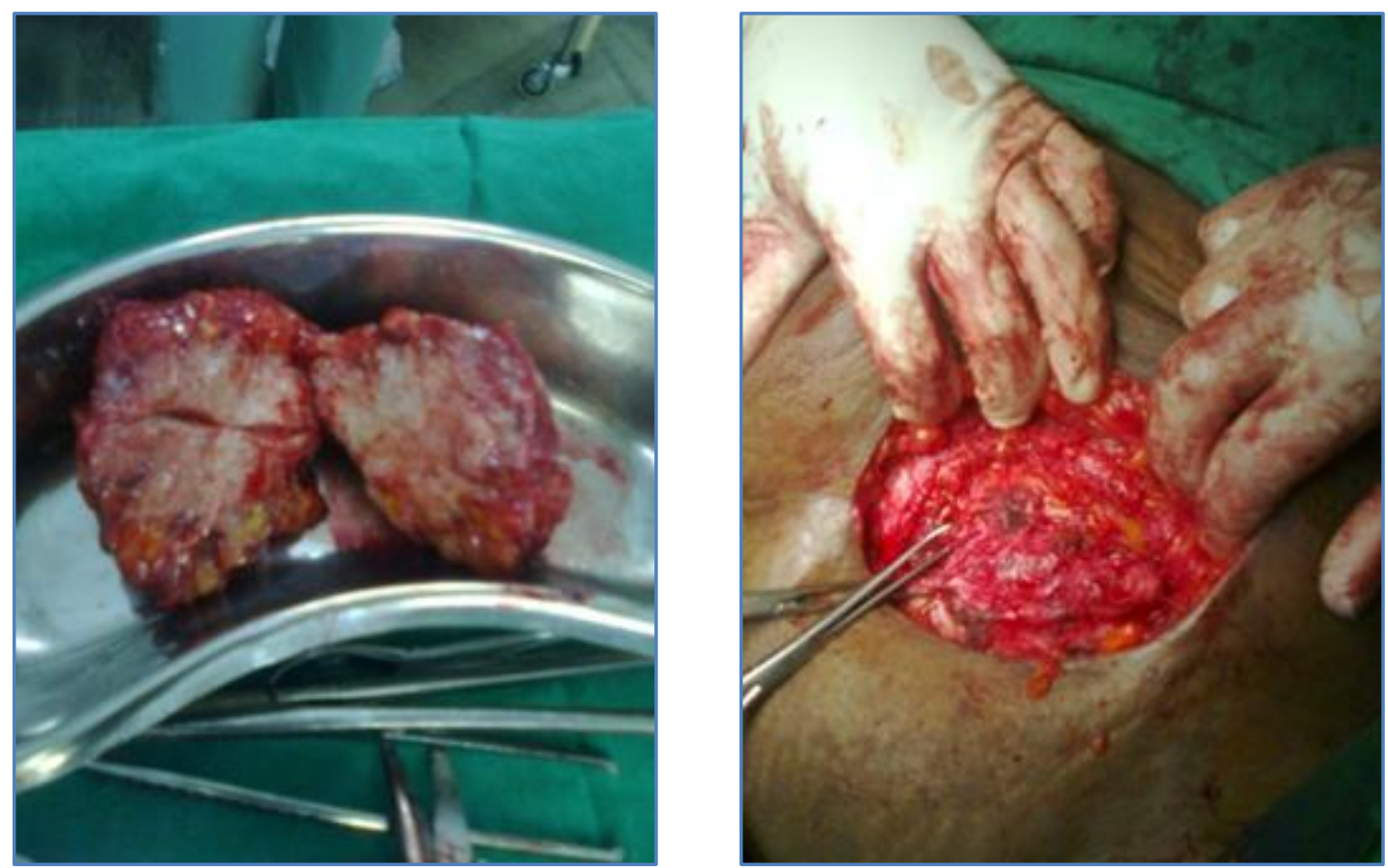

Figure 3 and 4: Excised endometrioma and post excision of scar endometrioma of Case 1 


\section{CASE REPORT}

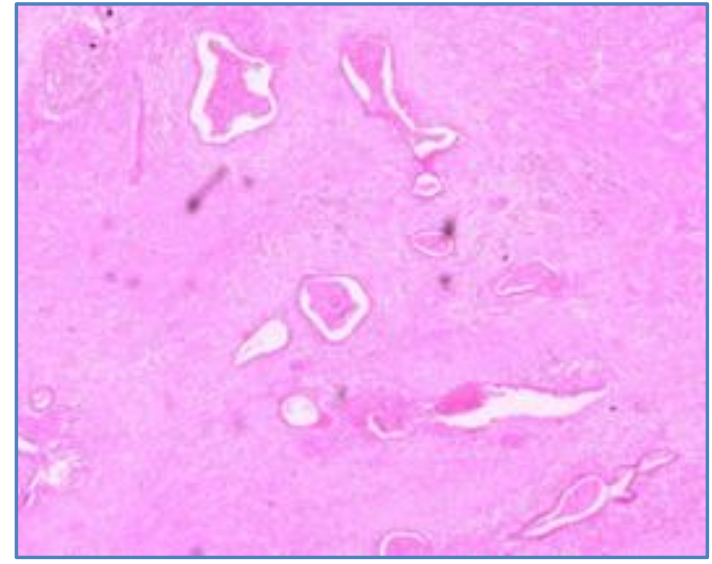

Fig. 5

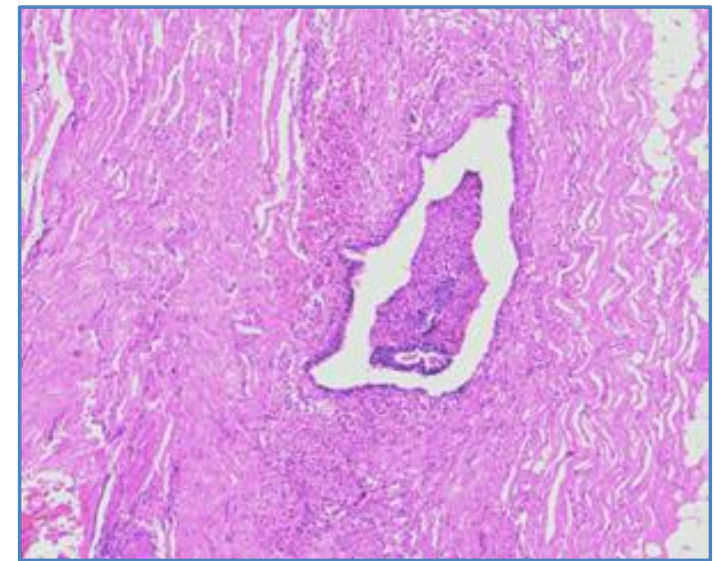

Fig. 7

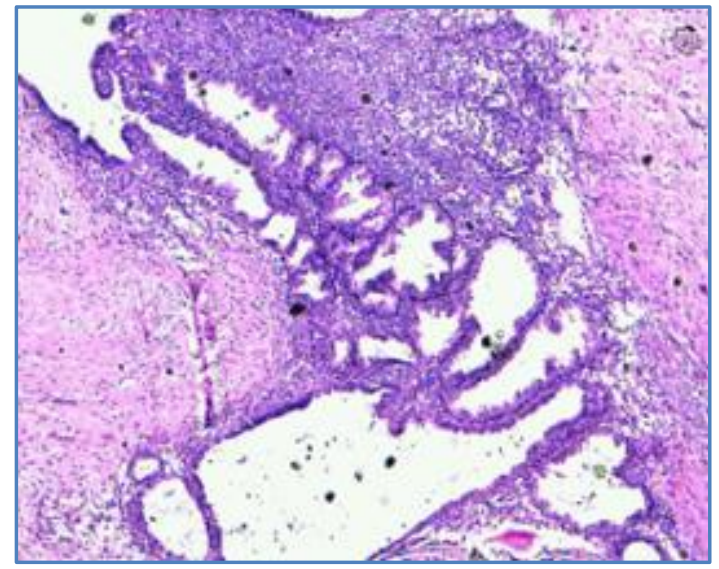

Fig. 6

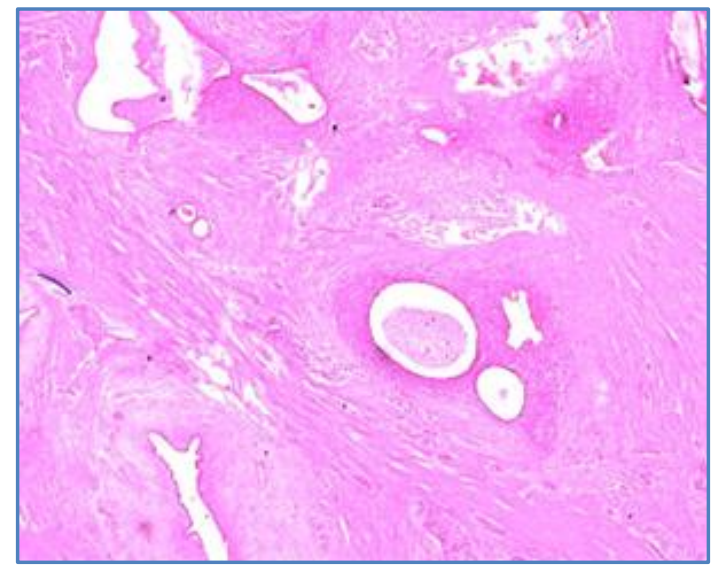

Fig. 8

\section{REFERENCES:}

1. Williams gynecology, Edited by John O Schorge et al McGraw Hill Medical, 2008, $1^{\text {st }}$ ed, chapter $10, \mathrm{p} 225$.

2. Howkins and Bourne Shaws text book of gynaecology, Edited by VG Padubidri et al, $15^{\text {th }}$ ed, 2011, Chapter 34, p 466.

3. Ding Dah-Ching et al. Scar endometriosis at the site of caesarean section, Taiwanese Journal of Obstetrics and Gynecology, 2006: 45(3); $247-249$.

4. Agarwal Manju, Gupta Deepak, Scar endometriosis in the vagina following episiotomy presenting as cyclical spotting, Journal of obstetrics and gynaecology India, 2004; 54(1).

5. Lahiri AK, Sharma K, Busiri N. Endometriosis of the uterine cesarean section scar: A case report. Indian J Radiol Imaging, 2008; 18: 66-8.

6. Picod G.Boulanger L.Bounova F, et al.Abdominal wall endometriosis after caesarean section report of fifteen cases. Gynaecol Obste. Fertil. 2006; 34; 8-13. 


\section{CASE REPORT}

7. Jeffcoates principles of gynaecology, Edited by Prata Kumar et al, 2008, 7 th international ed, chapter 22, p371, 372.

8. Goel P, Sood S S, Romilla, Dalal A. Cesarean scar endometriosis - Report of two cases. Indian J Med Sci 2005; 59: 495-8.

\section{AUTHORS:}

1. Onimi Syamala

2. G. Usha Rani

\section{PARTICULARS OF CONTRIBUTORS:}

1. Associate Professor, Department of Obstetrics and Gynaecology, SRMC and RI, Porur, Chennai.

2. Professor, Department of Obstetrics and Gynaecology, SRMC and RI, Porur, Chennai.

\section{NAME ADDRESS EMAIL ID OF THE} CORRESPONDING AUTHOR:

Dr. Syamala Onimi, Associate Professor, Department of Obstetrics and Gynaecology, SRMC and RI,

Porur, Chennai-600116, Tamilnadu.

Email: syamalapitani@yahoo.com

Date of Submission: 06/10/2014. Date of Peer Review: 07/10/2014. Date of Acceptance: 20/10/2014. Date of Publishing: 23/10/2014. 